\title{
ADENOID CYSTIC CARCINOMA OF PARANASAL SINUS - A RARE CONDITION
}

\author{
M. Muniraju1, Kailash N², Faiz M³ ${ }^{3}$ Raziya Roshni B ${ }^{4}$
}

HOW TO CITE THIS ARTICLE:

M Muniraju, Kailash N, Faiz M, Raziya Roshni B. "Adenoid cystic carcinoma of paranasal sinus - a rare condition". Journal of Evolution of Medical and Dental Sciences 2013; Vol2, Issue 38, September 23; Page: 7333-7336.

ABSTRACT: Adenoid cystic carcinoma of the paranasal sinuses is not a very common condition. It tends to arise from the maxillary antrum and can infiltrate into the surrounding tissue. They demonstrate perineural invasion into the maxillary and mandibular branches of trigeminal nerve.

KEYWORDS: Adenoid cystic carcinoma, paranasal sinuses, malignancy / radiation.

INTRODUCTION: Adenoid cystic carcinoma has been first described in French literature by three French men, Robin, Lorain and LaBulin and it has been nearly 100 years to understand it fully. In 1853 and 1854 they published two articles about this unusual tumour of head and neck region. In 1859 Bilroth gave it a description of pathology and coined the term "cylindroma" and also made a note of its tendency to recur. The malignant nature of the tumour was identified by Spies in 1930's and he gave it the name "Adenoid Cystic Carcinoma". In 1974, Dr. John Cornally and Dr. Digman described ACC as the most biologically destructive and unpredictable tumour of $\mathrm{H} \& \mathrm{~N}$ and even today it remains very difficult to treat.

Adenoid cystic carcinoma of paranasal sinuses is an uncommon tumor that accounts for less than $1 \%$ of all head and neck malignancies and $14 \%$ to $20 \%$ of all the adenoid cystic carcinomas arising in the head and neck. (1, 2) Of all malignant paranasal sinus tumours, 5 to $15 \%$ are adenoid cystic carcinomas. (4) As with other sinus tumors, its onset can be insidious. (6) On initial evaluation, most patients have advanced disease. The complexity of the local anatomy can make treatment difficult. (7)

Adenoid cystic carcinoma is a slowly progressive and relentless tumor that has a tendency to recur locally and metastasize distantly. (8,9) Recurrence and metastasis can occur even decades after treatment of the primary tumor. (10) This has led some authors to consider adenoid cystic carcinoma to be an incurable neoplasm.(11,12) The steadfastness of this tumor is partially attributable to its ability to extend through submucosal and fibrous tissue planes around the primary site and its tendency for perineural spread along major and minor nerves.(2,13) It is by examining the clinical characteristics, treatments, and outcomes of patients with adenoid cystic carcinoma of the paranasal sinuses or nasal cavity that we can develop an understanding of this rare and unusual malignancy.

CASE REPORT: 40 years male patient came to the outpatient department with history of progressive left sided nasal obstruction and intermittent scanty bleeding from the same side for 20 days. On examination of the nasal cavity there was a grayish white polypoidal mass in the left nasal cavity up to the inferior turbinate. On probing it was soft to firm in consistency, sensitive to touch, not mobile, and cannot be probed around the swelling.

On posterior rhinoscopy: A grayish white globular polypoidal mass filling posterior choana and extending into the nasopharynx was seen. 
Ear and throat examination no abnormality was detected.

Systemic examination was within normal limit.

Diagnostic nasal endoscopy was done: a smooth grayish white polypoidal mass in the left nasal cavity arising from the left (?) maxillary sinus and extending into the nasopharynx

Provisional diagnosis of Antrochoanal polyp / Malignancy of left maxillary sinus were arrived at.

Patient was further investigated with x-ray paranasal sinus which showed haziness in the left maxillary sinus.

CT scan of the paranasal sinus showed soft tissue density lesion arising from the left maxillary sinus and extending into the nasal cavity and nasopharynx, also showing left frontal sphenoid and ethmoid sinusitis(Figure: 1, 2). There was no enhancement of the mass with contrast.
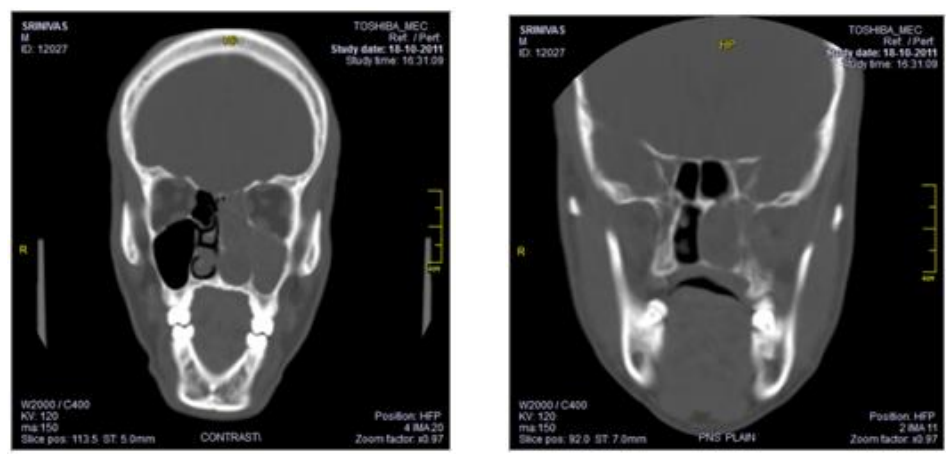

Figure no. 1, 2

Pre operative biopsy was not done since the clinical, endoscopic and radiological evaluation revealed features consistent with antrochoanal polyp.

Routine blood test and pre operative work up was done and patient was posted for endoscopic excision under general anaesthesia.

Intraoperative findings: A mass filling left nasal cavity, maxillary antrum and extending to the posterior choana. The mass was removed in toto endoscopically. Brisk bleeding was encountered which was controlled with anterior nasal packing. The specimen was subjected for histopathological examination.

\section{Histopathological examination:}
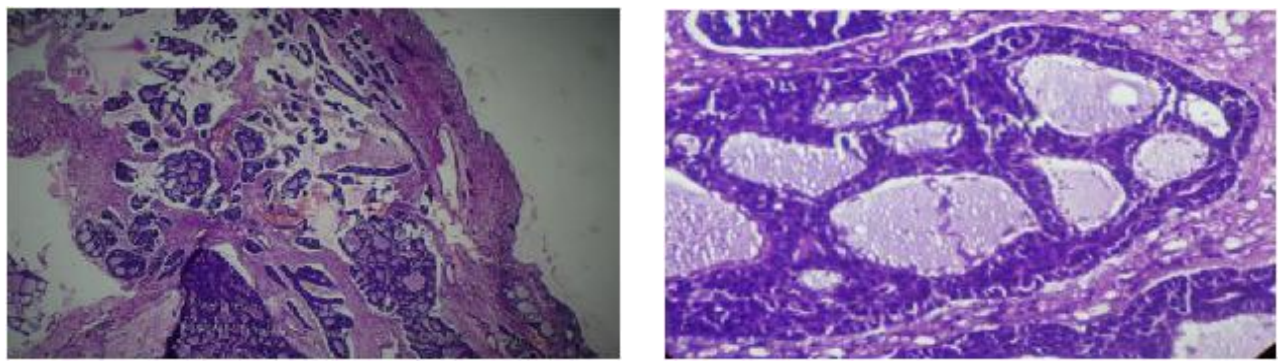

Figure no. 3, 4

Revealed islands of hyperchromatic basaloid epithelial cells containing multiple cysts like spaces filled with hyalinized eosinophilic product forming cribriform and tubular structures. The 
cells show scanty cytoplasm and round to ovoid basophilic nuclei with mild pleomorphism. The tumour cells showed infiltration into the stroma. No evidence of perineural invasion. The tumour margins were free of disease. Since the cribriform elements were predominant adenoid cystic carcinoma of cribriform variant was arrived at. The above features were suggestive of adenoid cystic carcinoma (cribriform variant) (Figure: 3 ).

The patient is being followed up for the last two years and thorough examination and endoscopic evaluation has not revealed any recurrence or metastases.

DISCUSSION: Adenoid cystic carcinoma originating in the mucous secreting glands of the paranasal sinuses and nasal cavity was described in 1962 by Tauxe et al as a cancer that "pursues [its] course relentlessly and maliciously." (15) They added that "few more horrible deaths can be imagined," as patients must endure "severe pain, paresthesia, blindness, dysphagia, deafness, dysarthria, and facial disfigurement that [occurs] over long periods and with ever increasing intensity." Of all patients with adenoid cystic carcinoma of the head and neck, those whose disease originates in the paranasal sinuses or nasal cavity have the poorest prognosis. ${ }^{(16,17)}$ This finding was described by Leafstedt et al in a review from the Roswell Park Cancer Institute more than 30 years ago. (16)

The factors for poor prognosis with ACC are a) Advanced tumour $(4,5)$ b) solid histological type $(6,7)$ c) nodal metastasis $(8) \mathrm{d}$ ) presence of positive margins e) perineural spread.

Because of the tumour propensity to spread in facial and perineural planes, complete surgical excision makes it more difficult. Aggressive removal is the choice of treatment.

Radiation may improve the prognosis in advanced disease. (4) Spiro et al (2) have mentioned that postoperative radiotherapy conferred no advantage, but others $(6,9)$ have given a study which proves that ACC is radiosensitive after surgical excision of tumour mass.

Histologically ACC is classified into three growth patterns based on tumour architecture, i.e., cribriform, tubular and solid. It is grade I if it is cribriform \& Tubular, grade II is $1 \%-30 \%$ solid and grade III is greater than $30 \%$ solid. Cribriform pattern is the most common. It has a classic Swiss cheese appearance. The tubular pattern has more glandular architecture and has the best prognosis. The solid or basaloid pattern shows sheets of cells with few or no luminal cells. This solid growth pattern has worse prognosis. (1)

Tumour growth is slow, but clinical cause is relentless, presents insidiously, advanced when diagnosed, operative intervention is feasible but multiple local recurrences occur frequently. Regional lymph nodes may not be always positive, but metastasis can occur to the lungs and bones. 5 year survival rates are high but 10-20 years survival rates are very low. (1)

Patients with P53 +ve tumour have worse prognosis than those with p53 -ve tumours. Other markers are C-kit, C erb-b2 and intercellular adhesion molecule. (1)

\section{REFERENCES:}

1. Kim KH, Sung MW, Chung PS, at el. Adenoid cystic carcinoma of the head and neck. Arch Otolaryngol Head Neck Surg 1994; 120:721-6.

2. Haddad A, Enepekides DJ, Manolidis S, Black M. Adenoid cystic carcinoma of the head and neck: A clinicopathologic study of 37 cases. J Otolaryngol 1995; 24:201-5.

3. Spiro RH, Huvos AG, Strong EW. Adenoid cystic carcinoma of salivary origin. A clinicopathologic study of 242 cases. Am J Surg 1974; 128:512-20. 
4. Kim GE, Park HC, Keum KC, et al. Adenoid cystic carcinoma of the maxillary antrum. Am J Otolaryngol 1999:20:77-84.

5. Miller RH, Calcaterra TC. Adenoid cystic carcinoma of the nose, paranasal sinuses, and palate. Arch Otolaryngol 1980:106:424-6.

6. Kraus DH, Roberts JK, Medendorp SV, et al. Non squamous cell malignancies of the paranasal sinuses. Ann Otol Rhinol Laryngol 1990; 99:5-11.

7. Naficy S, Disher MJ, Eselamado RM. Adenoid cystic carcinoma of the paranasal sinuses. Am J Rhinol 1999; 13:311-4.

8. Vikram B, Strong EW, Shah JP, Spiro RH. Radiation therapy in adenoid-cystic carcinoma. Int J Radiat Oncol Biol Phys 1984; 10:221-3.

9. Tran L, Sidrys J, Horton D, et al. Malignant salivary gland tumors of the paranasal sinuses and nasal cavity. The UCLA experience. Am J Clin Oncol 1989; 12:387-92.

10. Fordice J, Kershaw C, EI-Naggar A, Goepfert H. Adenoid cystic carcinoma of the head and neck: Predictors of morbidity and mortality. Arch Otolaryngol Head Neck Surg 1999; 12S:149-52.

11. Dal Maso M, Lippi L. Adenoid cystic carcinoma of the head and neck: A clinical study of 37 cases. Laryngoscope 1985; 95:177-81.

12. Chilla R, Schroth R, Eysholdt U, Droese M. Adenoid cystic carcinoma of the head and neck. Controllable and uncontrollable factors in treatment and prognosis. ORL J Otolaryngol Relat Spec 1980; 42:346-67.

13. Goepfert H, Luna MA, Lindberg RD. White AK. Malignant salivary gland tumors of the paranasal sinuses and nasal cavity. Arch Otolaryngol 1983; 109:662-8.

14. American Joint Committee on Cancer Staging. Cancer Staging Handbook. AJC Cancer Staging Manual. 5th ed. Philadelphia: Lippincott-Raven, 1998:51-5.

15. Tauxe WN, McDonald JR. Devine KD. A century of cylindromas. Arch Otolaryngol 1962; 75:94-106.

16. Leafstedt SW, Gaeta JF, Sako K, et al. Adenoid cystic carcinoma of major and minor salivary glands. Am J Surg 197 l; 122:756-62.

\section{AUTHORS:}

1. M. Muniraju

2. Kailash $\mathrm{N}$.

3. Faiz M.

4. Raziya Roshni B.

\section{PARTICULARS OF CONTRIBUTORS:}

1. Associate Professor, Department of ENT, Dr. B.R. Ambedkar Medical College, Bangalore.

2. Professor, Department of ENT, Dr. B.R. Ambedkar Medical College, Bangalore.

3. Senior Resident, Department of ENT, Dr. B.R. Ambedkar Medical College, Bangalore.

4. Senior Resident, Department of ENT, Dr. B.R. Ambedkar Medical College, Bangalore. 